\title{
Motivation and Mental Toughness among Table Tennis Athletes: Achievement in Sports Performance
}

\author{
Jonathan V. Pagdato $^{\# 1}$, Milla Gallardo ${ }^{* 2}$, Stephen A. Fadare ${ }^{\# 3,}$ Hendely A. Adlawan ${ }^{\# 4}$ \\ ${ }^{1,2,3}$ College of Sport Physical Education and Recreation, Mindanao State University (Main) Marawi, \\ Philippines.
}

\begin{abstract}
This descriptive-type study assessed the motivation and mental toughness among table tennis athletes and their achievements in sports performance. The respondents of this study were 68 table tennis varsity athletes who officially played in the singles event during the Mindanao Association of State and Tertiary Schools (MASTS) Friendship Games in Tandag, Surigao Del Sur. The data were gathered using questionnaires and observation and were treated using frequency and percentage to measure the significant relationship between and among the variables. In addition, the Pearson Product Moment Correlation of Coefficient or Pearson $r$ was utilized. It was concluded that schools, universities, and college administrators must give adequate support and provide ample budgetary needs for the varsity athletes to participate in local, regional, and national competitions and tournaments. Government and institutions should equip, train, and manage competitive stress among athletes and enhance their mental capacity to handle performance during games.

The researchers concluded that institutions must also consider younger players in their selection process of the varsity. Based on the result of the study, more immature players were more motivated and highly mentally tough compared to the older players.
\end{abstract}

Keywords: Achievement motivation, mental toughness, sport performance, varsity athletes.

\section{INTRODUCTION}

Today, coaches, trainers, sports managers, sports psychologists, and athletes look into various edges and advantages to rise or soar high with the same goal: to win. One of the most critical factors that lead one to their goals is the drive. This drive is known as motivation. Motivation is excitement and resoluteness that leads one to strive, reach tremendous peaks, no matter what path of their life, be it - personal or professional (Atkinston, 1964). Also, it may come from an individual's internal or external source, which motivates is a constant need. Achievement motivation can best be comprehended by examining the meanings of "achievement" and "motivation." As Clark (2010) mentioned, it typically stresses the importance of accomplishment and attainment with the effort involved.

Moreover, achievement can be described as the energy used to overcome challenges and persevere to conquer a goal. On the other hand, motivation relates to an individual's reason for engaging in an activity, the degree to which an individual pursues the training, and the persistence of the individual (Clark, 2010).

Motivation is the primary driver for all individual's actions; it refers to the dynamics of one's behavior which involves the individual's needs, desires, and ambitions in life. With clarity of mind and firmness of purpose, mentally tough performers, as cited by Sheard (2013), aspire to be great. Settling for being good is never enough among these individuals. They know how to win and have the courage to stand tall in the face of adversity; it is not a denial of the problem but the efficiency of the response. Champions do ordinary things better than anyone else.

Mentally tough performers refuse to be intimidated; instead, they scare the opposition with their presence; these individuals make fewer mistakes and possess a work ethic, winning mentality, and self-confidence. But, again, it is about holding oneself together. Winning is not all that matters. The character also counts since they compete with talent, enthusiasm, guts, dignity, and integrity.

Research findings will help Schools, Universities, and Colleges give adequate support and provide budgetary requirements for the varsity athletes to join specifically in different local, regional, and national competitions or tournaments. Also, various institutions must select younger players. Based on the result of the study, younger players have more motivated and highly mentally tough compared to the older ones. 
DOI: $\underline{10.51386 / 25815946 / \text { ijsms-v4i3p114 }}$

Volume: 4 Issue: 3

May to June 2021

www.ijjsmsjournal.org

\section{LITERATURE REVIEW}

\section{A. Achievement Motivation}

Shaffer (2008) defined achievement motivation as the willingness to strive or succeed at challenging tasks and meet high accomplishment standards. The need for achievement is a stable, learned characteristic in which a person obtains satisfaction by striving for and attaining a high level of excellence. People with an increased need for achievement seek out situations to compete against some standards - be it grades, money, or winning a game and prove them successful. But they are not haphazard when it comes to picking their challenge. They tend to avoid situations where success will go too quickly and situations in which victory is unlikely. Instead, people high in achievement motivation generally chose tasks that are of intermediate difficulty.

Athletes who have a high achievement motivation tend to be persistent and hardworking. They can delay gratification to meet long-term goals and select careers that allow them to contend.

Many achieve the most when they have high expectations of success, incentives that reward competence, control over tasks, opportunities to achieve, and practical goals. These goals are more effective when specific, moderately challenging, and framed in terms of what must be done rather than what must be averted (Rogulj, 2006). High achievement motivation often manifests in an excellent level of stimulation in difficult situations and realistic aspiration levels (Rogulj, 2006). It is a sport that includes complex and accurate motor skills and suggested that psychological factors play a vital role in a competition, differentiating between successful and less successful teams or individuals. Achievement motivation is the need for greatness for its own sake, without regard for external rewards. Still, one's accomplishment might bring and is based on "reaching success and achieving all of our aspirations in life." Thus, children with high achievement motivation seek out challenging tasks that they know they can accomplish with effort and persistence (Briones et al., 2010).

Furthermore, Frankens (2007) noted that achievement motivation influences performance in sports like physical preparation, technique, tactics, and even lifestyle. Therefore, achievement motivation cannot be described as something that occurs during competitions but mainly as a trait of having a permanent character being formed during preceding weeks, months, and years. It is considered to be the "driving power of activity." It should be understood as a joint function of the motive power and the consequences of what a given individual expects of his actions. This function is a product of two tendencies that are to achieve success and to avoid failure. It was suggested by Atkinson and Feather (1966) that achievement motivation is a combination of two personality variables: the tendency to approach success and the tendency to avoid failure.

In line with the findings, Junaedi et al. (2021) proposed that to enhance Work motivation through Inspirational Motivation, individuals in institutional or team (specifically sportsmen and women) should provide selfdetermination, and coaching methods include components. (a) role models who can provide real-life examples of subordinates' behavior, raising persons' knowledge of the importance of working well, enjoying their work, and being innovative. Leaders must also establish a harmonious working environment conducive and inspires to constantly develop new things in carrying out duties/jobs by (b) setting high expectations (enthusiasm) for employees so that they carry out tasks with confidence. (c) Analytical thinking, i.e., developing an open attitude, continually encouraging subordinates to work hard, succeed, and be competitive in delivering the most delicate work for the organization's advantage, (d) taking into account the individual, such as paying attention to each subordinate, interacting effectively with all employees, and making all decisions with the impact on subordinates in mind.

According to Parker and Johnson (1981), an individual attainment motive may be seen as a character trait. Each person has different extents of achievement motivation. Great achievers may be categorized as steered, striving for success, competitive, or taking charge. Low achiever may be seen as quitters, non-participant, or failure. Each person approaches each situation with a unique combination of several achievement motives. Magda (1962) pointed out that people with high motivation levels will tell stories of success based on work and accomplishment. People with low levels of motivation tell stories of dreams and wishes where failure often results. 
DOI: $\underline{10.51386 / 25815946 / \text { ijsms-v4i3p114 }}$

Volume: 4 Issue: 3

May to June 2021

www.ijsmsjournal.org

\section{B. Mental Toughness}

Many coaches are becoming aware of the importance of developing mentally tough performers and are designing programs to develop mental toughness in their athletes. For example, Gould et al. (1987) conducted a study in which $82 \%$ of coaches rated mental toughness as the most critical psychological attribute or characteristic in determining success in wrestlers. Unfortunately, the results also showed that only $9 \%$ of those same coaches had successfully developed mental toughness in their athletes. "The common lack of clearness and precision nearby the term mental toughness is unfortunate since it is debatably one of the most important psychological attributes in achieve performance excellence" (Jones et al., 2002).

Mental preparation is essential to any competitive event. Athletes who are not mentally prepared for the competition will experience mental lapses during the games. One example of the effects of insufficient mental preparation is those players in lawn tennis who could not sustain their concentration long enough to win a tiebreaker. Likewise, in baseball, some hitters settled into a state of mind that rendered them unable to hit a particular pitch, even though they had the physical ability to do. The inability to concentrate can hinder sports performance (Llewellyn \& Blucker, 1982). Moreover, mental toughness consistently emerges as one of the most important psychological characteristics of sport. It shows that mental toughness is imperative for peak sports performance.

Gould et al. (1987) state that mental toughness is an important psychological characteristic of sports performance. Unfortunately, a lot of acknowledge the importance of mental toughness, but few fully appreciate it. "While athletes and coaches often talk about mental toughness, seldom has it been precisely defined. Coaches and athletes use this word every day without a clear considerate of its components or what it means to be mentally tough." Mental toughness is almost certainly one of the most used but least unspoken terms used in applied sport psychology." Furthermore, often connected with peak presentation is the psychological construct of mental hardiness. Indeed, in a study of the psychological characteristics of Olympic champions, Gould et al., (2002) identified mental toughness as the mental skill factor most frequently cited as a significant contributor to sports performance enhancement. Mental toughness is intuitively appealing and used equally generously by players, coaches, and sports media.

Fourie and Potgieter (2002) analyzed written responses from 131 expert coaches and 160 elite athletes. Their analysis identified eleven components of mental toughness: motivation level, coping skills, confidence maintenance, cognitive skill, discipline and goal-directedness, competitiveness, possession of prerequisite physical and mental requirements, team unity, preparation skills, psychological hardiness, and ethics.

Deci and Ryan (1985) provide a theoretical grounding to understand this internally derived motivation and mental toughness. Their self-determination motivation theory defines inherent motivation as a motivation to join in an activity for the sheer gratification it provides to the member. Thus, the individual is motivated to perform for the internal sense of happiness that the participation offers. From the results reported here, it is undoubtedly true that motives for mental toughness are internally derived (i.e., personal bests and task value). Therefore, theory relating to internal motivations is relevant in the development of mental toughness.

Aside from those mentioned above, mental toughness has the natural or developed psychological edge that enables: 1) generally, cope better than your opponents with the many demands (competition, training, lifestyle) that sport places on a performer; and, 2) Especially, be more consistent and better than your opponents in remaining restricted, directed, confident, and in control under (Jones et al., 2002).

Lastly, Crust and Clough (2005) found that individuals who scored higher on total mental toughness, control, and confidence were significantly more likely to tolerate a physical endurance task for longer than those individual who scored lower on these factor.

\section{METHODOLOGY AND METHODS}

This study employed a descriptive study type. The respondents of this study were the table tennis varsity athletes, composed of 68 athletes with 38 males and 30 females using total enumeration, in the city of Tandag Surigao Del Sur, Mindanao. The research instrument used was a questionnaire in gathering data for this study 
and observation of participants in the table tennis tournaments. The data collected were treated using descriptive statistics in the form of frequency and percentage in the survey. And to measure the significant relationship between and among the variables, Pearson Product Moment Correlation of Coefficient or Pearson r was utilized. In collecting the data for this study, the research made the following steps: The researcher prepared all the needed letters and questionnaires used in the data collection. Before the tournament, the researcher submitted a letter request addressed to the Table Tennis Tournament Manager for the conduct of the study. Upon approval, the researcher personally gave another letter request to the respective Table Tennis coaches of different universities to ask support and permission to observe their athletes

\section{RESULTS AND DISCUSSION}

The following tables present the findings of results and discussions regarding the profile and the correlation of the variables used.

\section{A. Achievement Motivation} motivation.

Table 1 shows the frequency and percentage distribution of the respondents according to achievement

Table 1. Distribution of the Respondents According to Achievement Motivation

\begin{tabular}{|l|l|c|c|}
\hline \multicolumn{1}{|c|}{ Score Range } & \multicolumn{1}{|c|}{ Achievement Motivation } & $\begin{array}{c}\text { Frequency } \\
(\mathbf{f})\end{array}$ & $\begin{array}{c}\text { Percent } \\
(\boldsymbol{\%})\end{array}$ \\
\hline $28-48$ & Very Low Achievement Motivation & 0 & 0.00 \\
\hline $49-69$ & $\begin{array}{l}\text { Low Achievement } \\
\text { Motivation }\end{array}$ & 0 & 0.00 \\
\hline $70-90$ & Moderate Achievement Motivation & 15 & 22.10 \\
\hline $91-111$ & $\begin{array}{l}\text { High Achievement } \\
\text { Motivation }\end{array}$ & 52 & 76.50 \\
\hline $112-132$ & Very High Achievement Motivation & 1 & 1.50 \\
\hline & Total & 68 & 100.00 \\
\hline
\end{tabular}

The results indicated that a high majority of the respondents, with a frequency of 52 or $76.50 \%$, got a high level of achievement motivation. This is followed by 15 respondents with a percentage of $22.10 \%$ who have reached a moderate level of achievement motivation. On the other hand, only 1 of the respondents, or 1.5\%, got a very high level of achievement motivation. Therefore, no respondent has low and shallow achievement motivation. This means that all of the athletes possess the desire to win, albeit in varying degrees.

According to Apruebo (2005), high and low achievers can be distinguished by their effort during competition, persistence, and performance. High achievers usually adopt mastery goals. They attribute success to stable and internal factors likeability and effort. On the other hand, low achievers judge themselves more on outcome goals and attribute successes to luck or ease and failure to low ability.

Moreover, Carey (2000) mentioned that achievement motivation is the most significant predictor of performance and is essential in competition. Also, Taylor (1994) treated motivation as the base of a pyramid towards success in sports. The higher level of achievement motivation the bigger, the chance to win in a sports competition.

\section{B. Mental Toughness}

Table 2 displays the frequency and percentage distribution of the respondents according to achievement motivation. 
DOI: $\underline{10.51386 / 25815946 / \mathrm{ijsms}-\mathrm{v} 4 \mathrm{i} 3 \mathrm{p} 114}$

Volume: 4 Issue: 3

May to June 2021

www.ijsmsjournal.org

Table 2. Distribution of the Respondents According to Mental Toughness

\begin{tabular}{|l|l|l|l|}
\hline Score Range & Mental Toughness & Frequency (f) & Percent (\%) \\
\hline $30-54$ & Very Low Mental Toughness & 0 & 0.00 \\
\hline $55-79$ & Low Mental Toughness & 3 & 4.40 \\
\hline $80-104$ & Average Mental Toughness & 43 & 63.20 \\
\hline $105-129$ & High Mental Toughness & 22 & 32.40 \\
\hline $130-150$ & Very High Mental Toughness & 0 & 0.00 \\
\hline & Total & 68 & 100.00 \\
\hline
\end{tabular}

The table above showed that the majority, $63.20 \%$ or 43 out of 68 respondents, have an average level of mental toughness, followed by high mental toughness with 22 respondents out of 68 or $32.40 \%$. Lastly, only 3 out of 68 or $4.40 \%$ of respondents have low mental toughness. Moreover, the data showed that not even one respondent scored very low and very high in the test that assesses mental toughness.

The study revealed that the great majority of the respondents who participated during the 2016 MASTS Friendship Game, specifically in the event of table tennis, were considered mentally tough based on their scores on the said test.

Jones and Connaughton (2007) stated that mentally tough performers love the pressure of competition. The ideal mentally tough performer is perceived as adapting to or coping with any unplanned adverse situation and performing optimally no matter what was thrown at them. Mentally tough performer remains committed to the faith of aim achievement until every possibility of success had passed.

Furthermore, often associated with peak performance is the psychological construct of mental toughness. Indeed, in a study of the psychological characteristics of Olympic champions, Gould et al (2002) identified mental toughness as the mental skill factor most frequently cited as a significant contributor to sports performance enhancement. Mental toughness is intuitively appealing and used equally generously by players, coaches, and sports media.

Lastly, Crust and Clough (2005) found that individuals who scored higher on total mental toughness, control, and confidence were significantly more likely to tolerate a physical endurance task for longer than those individuals who scored lower on these factors.

\section{Sports Performance}

Table 3 shows the frequency and percentage distribution of the respondents according to their sports performance.

Table 3. Distribution of the Respondents According to Sports Performance

\begin{tabular}{|l|c|c|}
\hline \multicolumn{1}{|c|}{ Sports Performance } & Frequency (f) & Percent (\%) \\
\hline Eliminated & 36 & 52.90 \\
\hline Quarter-Finalist & 16 & 23.50 \\
\hline Semi-Finalist & 8 & 11.80 \\
\hline Finalist & 4 & 5.90 \\
\hline Champion & 4 & 5.90 \\
\hline Total & 68 & 100.00 \\
\hline
\end{tabular}

Table 3 presents the distribution of the respondents in terms of their sports performance. It shows respondents, 36 out of 68 or $52.90 \%$ played only in the elimination round, 16 respondents or $23.50 \%$ reached the quarterfinals, while eight respondents, or $11.80 \%$, played in the semi-finals. On the other hand, four respondents, or $5.90 \%$, got the championship match for both the Male and Female categories. 
DOI: $\underline{10.51386 / 25815946 / \mathrm{ijsms}-\mathrm{v} 4 \mathrm{i} 3 \mathrm{p} 114}$

Volume: 4 Issue: 3

May to June 2021

www.ijjsmsjournal.org

In terms of sports performance of the athletes were taken from the Single matches. The mode of the tournament during the Elimination Round was Round Robin. From the Quarterfinal Round to the Championship Round, it was Single Elimination. Every match was highly contested and hard-fought because the winner in every game automatically qualifies to the next round, the more chances of going into the next round.

\section{Correlation between Moderating and Independent Variables}

Table 4. Correlation between Moderating Variables and Independent Variable

\begin{tabular}{|l|l|l|l|l|l|l|l|l|}
\hline & \multicolumn{4}{|l|}{ Achievement Motivation } & \multicolumn{3}{l|}{ Mental Toughness } \\
\cline { 2 - 10 } & $\begin{array}{l}\mathrm{r}- \\
\text { value }\end{array}$ & $\begin{array}{l}\mathrm{x}^{2}- \\
\text { value }\end{array}$ & $\begin{array}{l}\mathrm{p}- \\
\text { value }\end{array}$ & $\begin{array}{l}\text { Decisio } \\
\mathrm{n}\end{array}$ & $\begin{array}{l}\mathrm{r}- \\
\text { value }\end{array}$ & $\begin{array}{l}\mathrm{x}^{2}- \\
\text { value }\end{array}$ & $\begin{array}{l}\mathrm{p}- \\
\text { value }\end{array}$ & Decision \\
\hline Age & -0.305 & & 0.012 & $*$ & -0.300 & & 0.014 & $*$ \\
\hline Ethnicity & & 20.60 & 0.412 & NS & & 22.14 & 0.333 & NS \\
\hline $\begin{array}{l}\text { Length of Playing } \\
\text { Experience }\end{array}$ & 0.022 & & 0.858 & NS & -0.046 & & 0.714 & NS \\
\hline Sex & & 0.375 & 0.540 & NS & & 0.344 & 0.557 & NS \\
\hline
\end{tabular}

Legend: if p-value $>0.05$, not significant (NS)

If p-value $<0.05$, significant $(*)$

The data between the moderating variables of age, ethnicity, playing experience, and sex, and the independent variables of achievement motivation and mental toughness using Pearson Product Moment Correlation of Coefficient popular known as Pearson $r$ and Kruskal-Wallis Test.

The findings revealed that the respondents' age is significant with achievement motivation obtaining the r-value of -0.305 and p-value of 0.012 . Thus, there is a negative correlation between the age of the respondents and achievement motivation. Furthermore, it implies that as the age of the respondents increases, the level of achievement motivation decreases.

Moreover, the respondents' age and mental toughness are also significantly correlated, obtaining the r-value of 0.300 and p-value of 0.014 . There is no correlation between the age of the respondents and the mental toughness. It means that as the age of the respondents increases, the level of mental toughness decreases.

For these results, the null hypothesis, which stated that "There is no significant relationship between age and achievement motivation; age and mental toughness is, therefore, rejected.

It shows that athletes who started playing at an early stage and the younger period have a better achievement motivation and mental toughness than the athletes who started playing at the older location. Since, based on the age level of the respondents, the majority of them were in the age range from 18 years old to 19 years old compared to the rest of the respondents.

E. Correlation between Moderating and Dependent Variables

Table 5. Correlation between Moderating Variables and Dependent Variable

\begin{tabular}{|l|l|l|l|l|}
\hline \multirow{2}{*}{$\begin{array}{l}\text { MODERATING } \\
\text { VARIABLES }\end{array}$} & \multicolumn{2}{|l|}{ DEPENDENT VARIABLE } \\
\cline { 2 - 5 } & \multicolumn{2}{|l|}{ Sports Performance } & p-value & Decision \\
\cline { 2 - 5 } & r-value & $\mathrm{x}^{2}$-value & 0.129 & NS \\
\hline Age & 0.187 & & 0.315 & NS \\
\hline Ethnicity & & 85.54 & 0.042 & $*$ \\
\hline $\begin{array}{l}\text { Length of Playing } \\
\text { Experience }\end{array}$ & 0.028 & & & NS \\
\hline Sex & & 0.068 & 0.795 & \\
\hline
\end{tabular}

Legend: if p-value $>0.05$, not significant (NS)

If p-value $<0.05$, significant $(*)$ 
DOI: $\underline{10.51386 / 25815946 / \mathrm{ijsms}-\mathrm{v} 4 \mathrm{i} 3 \mathrm{p} 114}$

Volume: 4 Issue: 3

May to June 2021

www.ijssmsjournal.org

Table 4 reflects that there is no significant relationship between sports performance as the dependent variable and the moderating variables such as age, ethnicity, and sex, as revealed by the r-value of $0.187, \mathrm{x}$-values of 85.54 and 0.068 , respectively, and its corresponding p-values of $0.129,0.315$ and 0.795 , respectively. In addition, the findings indicated that the respondents' sports performance is not affected by age, whether one is as young as 16 years old or as old as 25 years old, one's ethnic group affiliation, or whether a player is a male or female.

Therefore, the null hypothesis stated that "There is no significant relationship between age, ethnicity, and sex and sports performance, is at this moment accepted.

On the other hand, the length of playing experience showed a significant correlation with sports performance, with an R-value of 0.028 and a p-value of 0.042 . Thus, it implied that the size of the playing experience could affect the sports performance of the respondents. Furthermore, as the length of playing experience in terms of the number of years increases, sports performance also increases. Therefore, it is revealed in this study that playing expertise in table tennis is a factor to be considered in determining the sports performance of the respondents.

The null hypothesis, which stated that "There is no significant relationship between the length of playing experience and sports performance is at this moment, accepted.

\section{F. Correlation between Independent Variables and Dependent Variables}

Table 6. Correlation between Independent Variable and Dependent Variable

\begin{tabular}{|l|c|c|c|}
\hline \multirow{2}{*}{$\begin{array}{l}\text { INDEPENDENT } \\
\text { VARIABLE }\end{array}$} & \multicolumn{2}{|l|}{ DEPENDENT VARIABLE } \\
\cline { 2 - 4 } & Sports Performance \\
\cline { 2 - 4 } & r-value & p-value & Decision \\
\hline Achievement Motivation & -0.011 & 0.931 & NS \\
\hline Mental Toughness & & & NS \\
\hline
\end{tabular}

Legend: if p-value $>0.05$, not significant $(\mathrm{NS})$

If p-value $<0.05$, significant $(*)$

As revealed in Table 2.3, no significant correlation existed between achievement motivation and mental toughness to sports performance of the respondents with R-values of -0.011 and -0.193 , respectively, and pvalues of 0.931 and 0.117 , respectively.

Results of the study indicated that achievement motivation and mental toughness are not directly related to the sports performance of the respondents in sports competition, particularly in table tennis. Thus, mental toughness is determined by the sports performance of the respondents. Furthermore, how low or high is the level of achievement, motivation, and mental toughness of the individual is not directly related to the sports performance.

The level of achievement motivation and the athletes' mental toughness revealed that most athletes were motivated and mentally challenging. Still, the result of the study has no significant relationship with achievement motivation, mental toughness, and sports performance. It means that most athletes lacked skills, preparation, and experience to have a good understanding.

Fourie and Potgieter (2002) analysed written responses from 131 expert coaches and 160 elite athletes. Their analysis identified eleven components of mental toughness: motivation level, coping skills, confidence maintenance, cognitive skill, discipline and goal-directedness, competitiveness, possession of prerequisite physical and mental requirements, team unity, preparation skills, psychological hardiness, and ethics. Thus, the null hypothesis stated that "There is no significant relationship between Sports Performance and the independent variables of achievement motivation and mental toughness, is, therefore, accepted. 
DOI: $\underline{10.51386 / 25815946 / \mathrm{ijsms}-\mathrm{v} 4 \mathrm{i} 3 \mathrm{p} 114}$

Volume: 4 Issue: 3

May to June 2021

www.ijsmsjournal.org

\section{CONCLUSIONS AND RECOMMENDATION}

\section{A. Conclusion}

Based on the study's finding, the researchers concluded that: (1) There is no significant relationship between ethnicity, length of playing experience and sex with achievement motivation and mental toughness" is accepted. However, only age had a substantial connection to achievement motivation, considerable to mental toughness. Therefore, there is no significant relationship between age and achievement motivation and mental toughness" is rejected. The connotation of the factual finding notifies that as the respondents' age increases, achievement motivation, and mental toughness decrease. (2) Moreover, the moderating variables of age, ethnicity, and sex showed no correlation. The only length of playing experience had a significant relationship to sports performance. Therefore, the null hypothesis is accepted. As the size of playing experience in terms of the number of years increases, sports performance also increases (3). Finally, achievement motivation and mental toughness had no significant relationship to sports performance. Therefore, the Ho3, which states that "there is no significant relationship between achievement motivation and mental toughness with sports performance," is accepted.

\section{B. Recommendations}

Based on the above results and conclusions, the researchers offered the following recommendations: Schools, Universities, and Colleges must support and provide budgetary requirements for the varsity athletes for them to join different local, regional, and national competition or tournaments to improve their skills, to be equipped and well-trained, to manage competitive stress and also to enhance their mental capacity to handle those pressures, stressors, and problems during the competition which contributes to their performance enhancement; different institutions must select younger players since based on the result of the study, younger players have more motivated and highly mentally tough compared to the older.

Parents should allow and expose their children to involve specifically and mainly in sports to enhance their skills and have a healthy lifestyle, reminding them that physical activities and sports are essential for a productive and useful life. Conduct further studies based on achievement motivation, mental toughness, and sports performance using more respondents and other psychological components.

\section{ACKNOWLEDGMENT}

This research will not have been possible without the support of our dear College Dean, Dr. Hendely A. Adlawan; her enthusiasm, knowledge, and exacting attention to detail have been an inspiration and kept our work on track from the first encountered. To our colleagues at the College of SPEAR Mindanao State University (Main), Marawi, Philippines, they shared valuable information on this study. We were also grateful for the insightful comments offered by the anonymous peer reviewers at IJSMS. The unselfishness and creativity of one and all have improved this research in innumerable ways and saved us from many errors, those that inevitably remain our entire responsibility. Finally, to our families for their prayers, encouragement, and support to complete this study, God bless you all.

\section{REFERENCES}

[1] Apruebo, R. A. (2005). Sports Psychology. Manila: UST Publishing House.

[2] Atkinson, J.W. (1964). An introduction to motivation. Princeton, NJ: Van Nostrand.

[3] Briones, E. C., \& Flores, W. D. T. (2010). Achievement Motivation and Self Efficacy of Senior Education Students of Two Colle ges in Lipa City.Retrieved February 9, 2020 from http://www.peaklearning.com/documents/PEAK_GRI_cornista-macasaet.

[4] Carey, J.R. (2000). Academic Achievement Motivation in African American College Football Players. An Investigation of Educational Expectations and Values. University of North Carolina, chapel hill. Retrieved February 10, 2020 from.http://scholar.lib.vt.edu/theses/available/etd11202005210233/unrestricted.pdf.

[5] Clark, G. L. (2010). Differences in the Domains of Achievement Motivation based on Gender and Developmental Group. Retrieve February 9, 2016 from http://www.peaklearning.com/documents/PEAK_GRI_cornista-macasaet.

[6] Crust, L. (2007). Mental toughness in sport: A review. International Journal of Sport and Exercise Psychology, 5(3), 270-290. 


\section{DOI: $\underline{10.51386 / 25815946 / i j s m s-v 4 i 3 p 114}$}

[8] Deci, E.L., \& Ryan, R.M. (1985). Intrinsic motivation and self-determination in human behaviour. New York: Plenum. Retrieved October 9, 2016 from http://www.sectiononewrestling.com/discovering_mental_toughness.

[9] Feather, N. (1966). A theory of achievement motivation. New York: Wiley and Sons.

[10] Fourie, S. \& Potgieter, J.R. (2002). The nature of mental toughness in sport. South African Journal for Research in Sport, Physical Education and Recreation 23(2):63-72.

[11] Frankens, R, E. (2007). Human Motivation. $6^{\text {th }}$ ed. Thomson Wadsorth, Austrilia. Retrieved February 20 , 2015 from http://t012.ntcpe.edu.tw/ezcatfiles/t012/171/Feltz/988_423457_16_ESSR.pdf

[12] Gould, D., Hodge, K., Peterson, K., \& Petlichkoff, L. (1987). Psychological foundations of coaching: similarities and differences among intercollegiate wrestling coaches. The Sport Psychologist, 1, 293-308.

[13] Gould, D., Dieffenbach, K \& Moffet, A. (2002). Psychological characteristics and their development in Olympic champions. Journal of Applied SportPsychology.14: 172-204.

[14] Junaedi, A., Sunaryo, W. \&, Notosudjono, D. (2021). Determination of Work Motivation, Organizational Culture and Transformational Leadership in Improving Innovativeness of a Regional Government Employees. International Journal of Science and Management Studies (IJSMS). DOI: 10.51386/25815946/ijsms-v4i1p102.

[15] Jones, G., Hanton, S. \& Connaughton, D. (2002). What is this thing called mental toughness? An investigation of elite sport performers. Journal of Applied Sport Psychology. Thomson, London. 205-218. Retrieved February 20 , 2015 from http://www.jssm.org/combat/2/6/v6combat2-6.pdf

[16] Jones, G. \& Connaughton, D. (2007). A Guide to the Harvard Referencing System for CQI Students. Harvard. Retrieved September 20, 2015 from http://www.eurojournals. Com/rjis_12_06.pdf.

[17] Llewelyn, J.H \& Buckler, A.J. (1982). Psychology of Coaching: Theory and Application. Surjeet Publications.

[18] Magda, A. (1962). Story Sequence Analysis - a new method of measuring motivation and predicting achievement. New York: Columbia University Press. Retrieved February 9, 2016 from http://www2.uwstout.edu/content/lib/thesis/2002/2002zenzent.

[19] Parker, J. \& Johnson, C. (1981). Affecting Achievement Motivation. Charlottesville, VA: University of Virginia. (ERIC Document $\begin{array}{llllllll}\text { Reproduction } & \text { Service } & \text { Number } & \text { ED } & 226 & 833) \text {. Retrieved } & \text { February } & 9 \text {, 2020 from }\end{array}$ http://www2.uwstout.edu/content/lib/thesis/2002/2002zenzent.

[20] Rogulj, N. (2006). Differences between competitively efficient and less efficient junior handball players according to their personality traits. Kinesiology journal, 2, 158-163. Retrieved September 20, 2020 from http://www.bbc.co.uk/news/education22126301

[21] Shaffer, D. R. (2008). Social and Personality Development (6thedition). California: Wadsworth Publishing Company. Retrieve February 9, 2020 from http://www.peaklearning.com/documents/PEAK_GRI_cornista-macasaet.

[22] Sheard, M. (2013) Mental Toughness. The mindset behind sporting achievement/2nd ed. 27 Church Road, Hove, East Sussex BN3 2FA.By Routledge. Retrieve February 9, 2020 from http://samples.sainsburysebooks.co.uk/9781136245244_sample_500727.

[23] Taylor, J. (1994). Pre-match routines. International tennis federation coaches Review, 4, 11. Retrieved March 20 , 2020 from http://eprints.ru.ac.za/3312/1/PATTISON-MSocSci-TR12-189.pdf 